\title{
An Electron Microscopic Analysis of Hippocampal Neurons Developing in Culture: Early Stages in the Emergence of Polarity
}

\author{
Jeffrey S. Deitch' and Gary A. Banker ${ }^{2}$ \\ 'Department of Cell Biology, UMDNJ-School of Osteopathic Medicine, Stratford, New Jersey 08084 and ${ }^{2}$ Department of \\ Neuroscience, University of Virginia Medical Center, Charlottesville, Virginia 22908
}

In culture, hippocampal neurons initially establish several short, minor processes. The initial step in the emergence of polarity is marked by the rapid and selective growth of one of these processes, which becomes the axon. Subsequently the remaining processes become dendrites. We examined the ultrastructure of hippocampal neurons before and after the emergence of the axon. The minor processes in cells that had not yet formed axons were somewhat variable in appearance, but we found no ultrastructural feature that indicated which minor process might become the axon. The emergence of the axon was marked by several changes in its ultrastructure. The axon contained a sevenfold lower density of polyribosomes than the minor processes. In addition, axonal growth cones contained a pronounced concentration of membranous elements that resembled endoplasmic reticulum, elements that were rare in the growth cones of minor processes. Axons and minor processes did not differ in microtubule density. In order to gauge how rapidly these ultrastructural changes occur, we examined cells with short axons that, from their length, were estimated to have emerged only hours earlier. The preferential exclusion of polyribosomes from the axon and the concentration of reticular membrane in the axonal growth cone were already evident in such cells.

These observations demonstrate that exclusion of ribosomes from the axon occurs early in development, about as soon as the axon can be identified. In contrast, previous work has shown that the differences in microtubule polarity orientation that distinguish mature axons and dendrites, and that have been proposed to account for the selective segregation of some constituents in neurons, first appear at a later stage of development (Baas et al., 1989). These observations also demonstrate that the accumulation of reticular membrane elements in growth cones, which has been noted previously, occurs preferentially in axonal growth cones and is closely correlated in time with the initial specification of the axon. The selective concentration of these elements

\footnotetext{
Received Jan. 27, 1993; accepted Apr. 15, 1993.

A significant portion of this research was performed while we were at the Department of Anatomy, Albany Medical College, Albany, NY; we are grateful to our colleagues there for their support and encouragement. This work was supported by NIH Grant NS17112 and by an equipment grant from the NSF (BNS 8607114). We thank Donna Tuttle for help with the quantitation and Paula Falk for photographic assistance.

Correspondence should be addressed to Dr. Gary Banker, Department of Neuroscience, University of Virginia School of Medicine, MR-4, Box 5148, Charlottesville, VA 22908.

Copyright (C) 1993 Society for Neuroscience $0270-6474 / 93 / 134301-15 \$ 05.00 / 0$
}

in axonal growth cones could be associated with the uniquely rapid rate of axonal growth.

[Key words: neurite outgrowth, ribosomes, smooth endoplasmic reticulum, growth cones, axon, dendrite]

Neurons are capable of generating and maintaining two separate structural compartments, axons and dendrites. As more of the physiological and molecular properties of axons and dendrites become known, the fundamental distinction between these two type of processes has become more evident (Llinas and Sugimori, 1980; Caceres et al., 1984; De Camilli et al., 1984; Huber and Matus, 1984; Binder et al., 1985; Dotti et al., 1987; Baas et al., 1988; Garner et al., 1988; Sargent, 1989). For most neurons, axonal and dendritic processes are readily distinguished by their shape, by their complement of membrane and cytoskcletal protcins, and by thcir synaptic polarity. Even in neurons whose synaptic polarity is mixed, such as those that participate in dendrodendritic synapses (Shepherd, 1979; Cheramy et al., 1981), the morphological and biochemical differences between axons and dendrites remain discernible.

In order to determine how a neuron establishes this compartmentation, we have studied the development of dissociated fetal rat hippocampal neurons in culture. The differentiation of these neurons follows a stereotyped progression, as seen by timelapse video recording of the development of individual cells (Dotti et al., 1988). After attaching to the substrate, lamellipodia form around the cell periphery (stage 1). The lamellipodia condense at several discrete spots from which short neurites, termed minor processes, emerge (stage 2). Minor processes extend and retract over short distances, but show little net growth for 12$24 \mathrm{hr}$. Then, rather abruptly, one minor process begins to grow rapidly, becoming four to five times longer than the others (stage 3 ). This process is the cell's axon. Over the next several days, the remaining minor processes grow longer and mature, becoming the cell's dendrites (stage 4).

Several observations suggest that at stage 2, when neurites first emerge, they are not specified to become either axons or dendrites. First, minor processes are indistinguishable from one another based on their light microscopic morphology and their pattern of growth. Second, antigens that are selectively distributed to axons or dendrites in mature hippocampal neurons, are uniformly distributed at stage 2 of development (Caceres et al., 1986; Goslin and Banker, 1990; Goslin et al., 1990; Fletcher et al., 1991). Finally, if the axon is severed, a minor process that otherwise would have become a dendrite instead becomes the new axon (Dotti and Banker, 1987; Goslin and Banker, 1989, 1990). Evidence of polarity first appears at stage 3 of develop- 
ment, when the axon acquires its unique growth properties (Dotti et al., 1988) and when GAP-43 and synaptic vesicle antigens become selectively distributed to this process (Goslin and Banker, 1990; Fletcher et al., 1991).

Although the ultrastructural differences between mature axons and dendrites are well known-for example, ribosomes are present in dendrites but excluded from axons - it is not known when during development these differences arise. To our knowledge, the ultrastructural changes associated with the development of neuronal polarity have not been systematically examined, either in situ or in culture. With specific reference to the cell culture model, the following questions arise. Are there ulstructural differences between neurites at stage 2 of development that might indicate which will become the axon? If not, when can they first be detected? Does the newly formed axon possess mature ultrastructural characteristics from the beginning, or is there a progressive change from minor process to axon? Are there ultrastructural features of the neurites or growth cones of cells at stage 3 of development that could account for the very different growth properties of axons and minor processes? These issues are the subject of the present report.

\section{Materials and Methods}

Cell culture. Methods for preparing hippocampal cultures have been described in detail previously (Goslin and Banker, 1991). Briefly, hippocampi were obtained from the brains of $18 \mathrm{~d}$ fetal rats, treated with $0.25 \%$ trypsin for $15 \mathrm{~min}$ at $37^{\circ} \mathrm{C}$, dissociated by repeated passage through a fire-polished Pasteur pipette, and plated onto glass coverslips that had been treated with poly-L-lysine $(1 \mathrm{mg} / \mathrm{ml})$. In most cases, cultures were prepared at a cell density of about 2000 cells $/ \mathrm{cm}^{2}(50,000$ cells per 60 $\mathrm{mm}$ culture dish). After the cells had attached, the coverslips were transferred cell side down to a dish containing a confluent monolayer of astroglial cells (prepared from neonatal forebrain), and maintained in minimal essential medium containing the N2 supplements of Bottenstein and Sato (1979), pyruvate $(0.01 \mathrm{mg} / \mathrm{ml})$, and ovalbumin $(1 \mathrm{mg} /$ $\mathrm{ml}$ ). Small dots of paraffin on the coverslips supported the neurons slightly above the underlying glial monolayer.

Several variations were explored to facilitate separation of the polymerized resin from the coverslip following embedding (for discussion of alternatives, see Banker and Goslin, 1991). In most experiments, glass coverslips were modified with dimethyldichlorosilane to make them more hydrophobic (Corey and Stevens, 1983) and then treated with poly-L-lysine in the usual way. Coverslips were immersed in dimethyldichlorosilane ( $1 \%$ in benzene) for $1 \mathrm{~min}$, drained of excess liquid, and dried in an oven at $60^{\circ} \mathrm{C}$. They were then rinsed in methanol and dried again. In some cases this procedure was repeated twice to increase the hydrophobicity. In a few initial experiments, cells were cultured on coverslips prepared from a fluorocarbon plastic film (Aclar 33C, Allied Chemical), which can be readily separated from epoxy resins (Masurovsky and Bunge, 1968; Bartlett and Banker, 1984a). However, some aspects of the development of hippocampal neurons occur abnormally on this substrate (Goslin and Banker, 1991), and we have discontinued its use.

Electron microscopy. Neurons were fixed and prepared for electron microscopy (EM) after $1-2 \mathrm{~d}$ in culture. Different cellular components were preserved best by different fixation procedures. In most experiments, glutaraldehyde $(70 \%)$ was added directly to the culture medium to give a final concentration of $3.5 \%$, and the neurons were fixed at $37^{\circ} \mathrm{C}$ for only 15 min. This fixative was slightly acidic $(\mathrm{pH} \sim 6.8$ ), but we found that this enhanced the contrast of microtubules and ribosomes. After 15 min some of this fixation medium was removed and mixed with osmium tetroxide to make a postfixation solution of $1 \% \mathrm{OsO}_{4}$ and $3.5 \%$ glutaraldehyde. Coverslips were transferred directly to the postfixing solution and left for $30 \mathrm{~min}$ at $37^{\circ} \mathrm{C}$ in the dark. This enhanced the membrane contrast in these young neurons and greatly reduced the occurrence of the artifactual membrane "blebs" that are commonly found following longer exposure to glutaraldehyde, particularly in growth cones (Hasty and Hay, 1978; Shelton and Mowzcko, 1978; Rees and Reese, 1981). However, the rapid introduction of osmium in this protocol disrupted actin microfilaments (Boyles et al., 1985). To preserve these structures better, some cultures were fixed for $1 \mathrm{hr}$ in $3.5 \%$ glutaraldehyde before addition of osmium. These initial steps in fixation were performed at $37^{\circ} \mathrm{C}$. This reduced the number and size of "blisters" or "pockets" that sometimes formed between the underside of the cell body and the substrate (see Fig. 1).

Following aldehyde fixation, the coverslips were rinsed well in phosphate buffer $(0.125 \mathrm{M}, \mathrm{pH} \mathrm{7.2)}$ and incubated for another $30 \mathrm{~min}$ in fresh $1 \% \mathrm{OsO}_{4}$ in phosphate buffer at $37^{\circ} \mathrm{C}$ in the dark. After rinsing in $3.6 \% \mathrm{NaCl}$ and in $\mathrm{H}_{2} \mathrm{O}$, the coverslips were stained in $5 \%$ aqueous uranyl acetate for $1 \mathrm{hr}$, rinsed again in $\mathrm{H}_{2} \mathrm{O}$, dehydrated in graded methanols, and left overnight in a 1:1 mixture of acetone and resin (Maraglas 732, Polysciences). The side containing the neurons was then coated with resin to a depth of 1-2 $\mathrm{mm}$ and polymerized. Then the coverslips were separated from the resin with a razor blade and the embedded cells stained with toluidine blue $(0.1 \%$ in borate buffer) for $5 \mathrm{~min}$ at $60^{\circ} \mathrm{C}$. Regions of the block containing the neurons of interest were photographed with phase-contrast optics, punched out with a leather punch, and remounted for sectioning.

When prepared in this way, the neuron and its processes lie immediately at the surface of the block. To make sectioning easier, a thin layer of Maraglas was spread onto the tip of the trimmed block, flattened with a small piece of Aclar, and polymerized. This gave 2-3 $\mu \mathrm{m}$ of empty plastic for adjusting the knife angle prior to reaching the neurites, and reduced the chance that the knife would pull parts of the cell out of the block with the first section. Serial sections ( $75-85 \mathrm{~nm}$ in thickness) were cut parallel to the plane of the substrate using a Reichert Ultracut $\mathrm{E}$, collected on formvar-coated slot grids, stained with uranyl acetate and lead citrate, and observed with a JEOL CX-100 electron microscope.

Approximately 75 neurons from more than 16 separate culture preparations were examined in the course of this work. Of these, 30 were selected for detailed analysis (see below).

Quantitative analysis of organelle density. A quantitative analysis was undertaken to determine if there were consistent differences in the ultrastructure of different types of processes and their growth cones, or if these features changed during development. A series of electron micrographs (at $8300 \times$ ) was prepared illustrating the full extent of individual cells fixed at developmental stages 2 and 3 . Prints wcre preparcd at a final magnification of $21,000 \times$ and assembled into a montage. Typically the second or third section up from the substrate was selected for this analysis because it contained the soma and neurites at their widest point and had the least substrate-related artifact.

The volume density of mitochondria was assessed by measuring the cross-sectional area occupied by mitochondria (using a GTCO DigiPad 5A digitizing tablet and SIGMASCAN software) and expressing this as a percentage of the cross-sectional area of the neurite. The density of polyribosomes (number of polyribosomes per square micrometer of neurite profile) was determined in a similar fashion; for counting purposes, a polyribosome was defined as a distinct cluster of three or more rounded, highly electron-dense spots about $15 \mathrm{~nm}$ in diameter. To quantify the relative density of microtubules and membrane-bound organelles within the processes, a pattern of oblique, parallel lines spaced 0.5 $\mu \mathrm{m}$ apart was placed along the full length of each neurite. We recorded the number of times a line intersected a microtubule and normalized this to the total length of the test lines that fell within the neurite; this measurement is directly proportional to the volume density of microtubules within the neurite (Weibel, 1979). A similar approach was used to determine the density of intracellular membranous organelles. A vesicle or tubule bisected by a test line was scored as two intersections, and a tangential intersection as one intersection. This gave an estimate of organelle membrane area per neurite volume, independent of the shape or contents of the organelle. All intracellular membranous elements except mitochondria [but including smooth endoplasmic reticulum (SER), coated vesicles, lysosomes, multivesicular bodies, and synaptic vesicles] were included in a single category. A distinctive concentration of smooth endoplasmic reticulum, which we refer to as "reticular membrane," was observed in some growth cones (see Results). This membrane was included in the estimation of total membrane described above, and its density also was quantified separately. Measurements of microtubule and membrane density were treated as relative values rather than adjusted to absolute densities (Weibel, 1979).

In our initial analysis, organelle density was calculated separately in adjoining, $5 \mu \mathrm{m}$ segments along the entire length of each of the neurites. Because we did not observe systematic proximal-to-distal variations in any of these measurements, we averaged them to obtain a single value for each neurite. For statistical analysis, measurements of the minor 


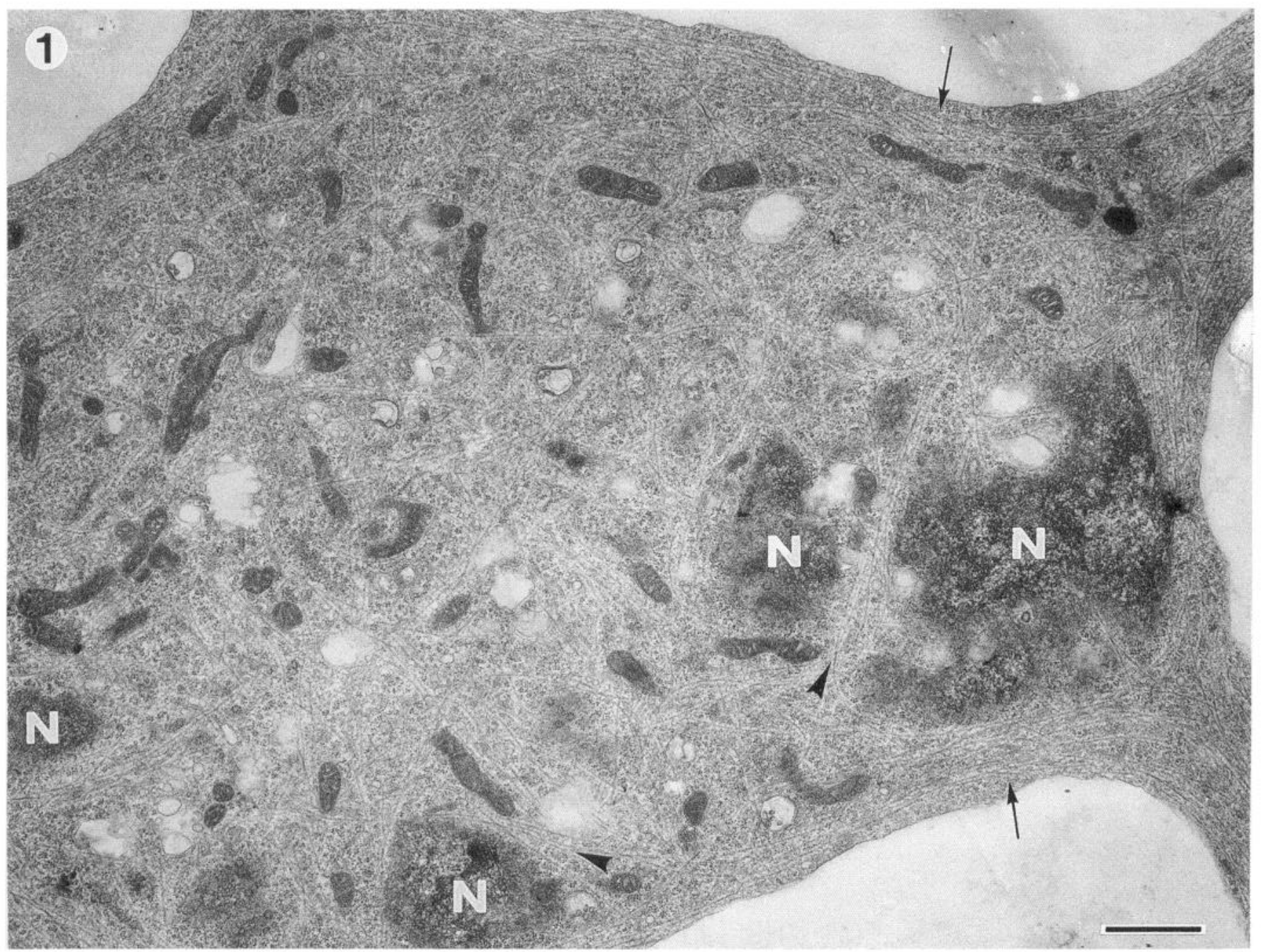

Figure 1. Somata of a stage 2 neuron sectioned close to the substrate. The "bottom" of the neuron consists mainly of mitochondria, a tangle of microtubules, and many polyribosomes. At this level, the nucleus $(N)$ is discontinuous, as if standing on feet that are separated by microtubules (arrowheads). Microtubules along the plasma membrane are typically more aligned (arrows), unlike those in the center of the cell. The subplasmalemmal microtubules are seen here sweeping into two minor processes. The large holes in the soma are artifacts of fixation caused by bubbles trapped between the cell and the substrate. Scale bar, $1 \mu \mathrm{m}$.

processes were averaged further to obtain a single value for the minor processes of each cell. Thus, for statistical analysis, each data point represented a single cell. For each of the ultrastructural features analyzed, all groups were initially compared using a one-way analysis of variance. When this indicated significance, post hoc comparisons of all possible pairs of groups were made using the Mann-Whitney $U$ test.

\section{Results}

\section{Organization of the cell body}

In general, the features of the cell bodies of hippocampal neurons in culture were similar to those described for cortical neurons at equivalent stages of development in situ (Nowakowski and Rakic, 1979; Peters et al., 1991; see also Bartlett and Banker, 1984a,b). In vitro, however, the ultrastructural organization of the cell body varied somewhat with distance from the substrate. Closest to the substrate, the cytoplasm contained predominantly polyribosomes and microtubules; few membranous elements were present (Fig. 1). Membrane-bounded "vacuoles" were also common near the lower surface of the cell. These appear not to be intracellular organelles, but rather "blisters" that formed between the cell and the substrate. Their prevalence varied with different fixation protocols (see Materials and Methods). Only fragments of the nucleus were visible at this level, indicating that the lower surface of the nucleus was irregular in contour. For the most part, microtubules coursed randomly through the soma, but an organized bundle of microtubules followed the perimeter of the soma and continued into the neurites. Bundles of microtubules were also observed between segments of the nucleus.

At higher levels (greater than $\sim 2 \mu$ m from the substrate) the nucleus no longer appeared fragmented. It occupied about half of the cell body, and its eccentric position was more obvious. Often the nucleus was kidney shaped, with a distinct indentation that faced the cytoplasmic pole of the cell and the Golgi complex (Fig. 2). The neurites ( 1 $\mu \mathrm{m}$ thick), which were much thinner than the soma ( $>5 \mu \mathrm{m}$ thick), were not visible in sections at this level.

The Golgi complex was the only component within the cell body whose configuration changed noticeably over the time course of this study. In neurons at stage 1 and stage 2 of development, the Golgi complex was spherical in outline, and the 

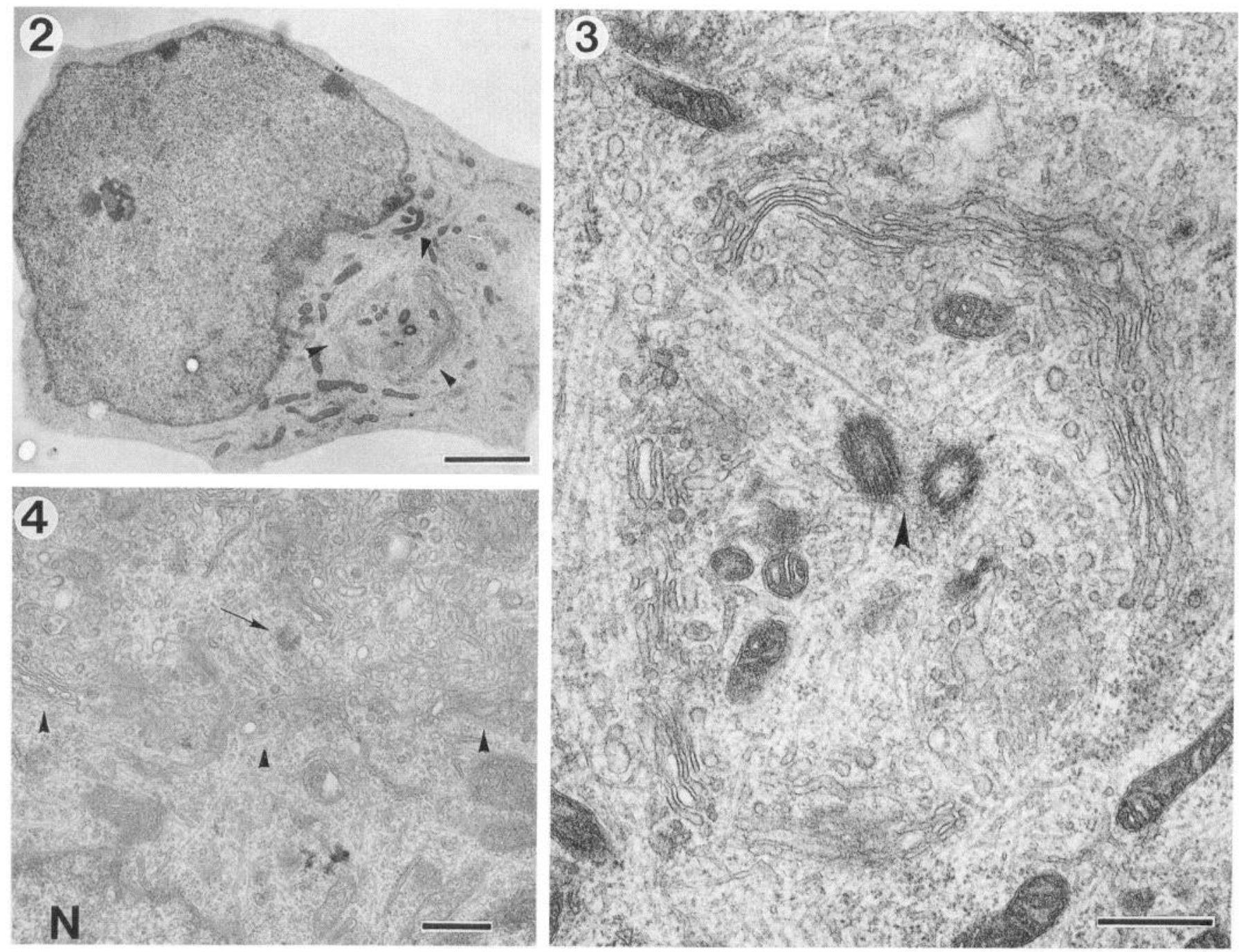

Figure 2. The soma of a neuron at stage 2 of development, sectioned at a higher level from the substrate, above the processes. The nucleus, which does not appear fragmented, lies at one pole of the neuron and possesses an indentation, which faces the opposite pole of the cell and the bulk of the cytoplasm. The Golgi complex (encircled by arrowheads) is spherical in shape and juxtaposed to the nuclear indentation. Scale bar, $2 \mu \mathrm{m}$.

Figure 3. Higher-magnification micrograph of the Golgi complex of the cell shown in Figure 2. The centrioles (arrowhead) lie at the center of the Golgi complex. Scale bar, $0.5 \mu \mathrm{m}$.

Figure 4. The Golgi complex in a stage 3 neuron. Elements of the Golgi complex occupy the upper half of the micrograph; the lower edge of the Golgi complex is delineated by arrowheads. The Golgi complex is still apposed to the nucleus $(N)$, but has become more convoluted and complex than in stage 2 cells. The centriole (arrow) is still associated with the Golgi complex. Scale bar, $0.5 \mu \mathrm{m}$.

centriole pair was often located at its center (Figs. 2, 3). At these stages, the Golgi complex was invariably juxtaposed to the indentation in the nucleus. With further development, the Golgi complex increased in size and became more convoluted in shape (Fig. 4). By late in stage 3 it no longer was confined to the region immediately adjoining the nuclear indentation, but occupied a larger fraction of the cytoplasm (see also Dotti and Banker, 1991). Light microscopic studies indicate that the Golgi complex continues to increase in size throughout the first week in culture (Goslin and Banker, 1990; K. Goslin and G. A. Banker, unpublished observations), ultimately coming to surround the nucleus, as it does during development in situ (Peters et al., 1991).

\section{Developmental stage 2-minor processes}

Stage 2 is marked by the formation of minor processes. These are short processes, typically five or six in number and less than

Figure 5. $a$, Phase-contrast micrograph of a stage 2 neuron embedded and stained with toluidine blue. Electron micrographs of the minor processes marked $b$ and $c$ are shown shown in panels $b$ and $c$. The arrow points to the growth cone shown in Figure 7a. Magnification, 1200×. $b$, An example of a wide minor process. The shaft of this minor process contains many polyribosomes and a weaving array of microtubules. Microtubules along the plasma membrane are more highly aligned (arrows). Membranous organelles are not prominent. Note the gradual transition from soma to process. $c$, An example of a narrow minor process. Most microtubules in the shaft of narrow minor processes are arrayed parallel to the shaft. Polyribosomes are present, as well as a few membranous organelles. The transition from soma $(S)$ is more abrupt than in $b$, as exemplified by the alignment of the microtubules. Arrowheads in $b$ and $c$ point to polyribosomes situated distally in the minor process. Scale bar $1 \mu \mathrm{m}$ for $b$ and $c$. 


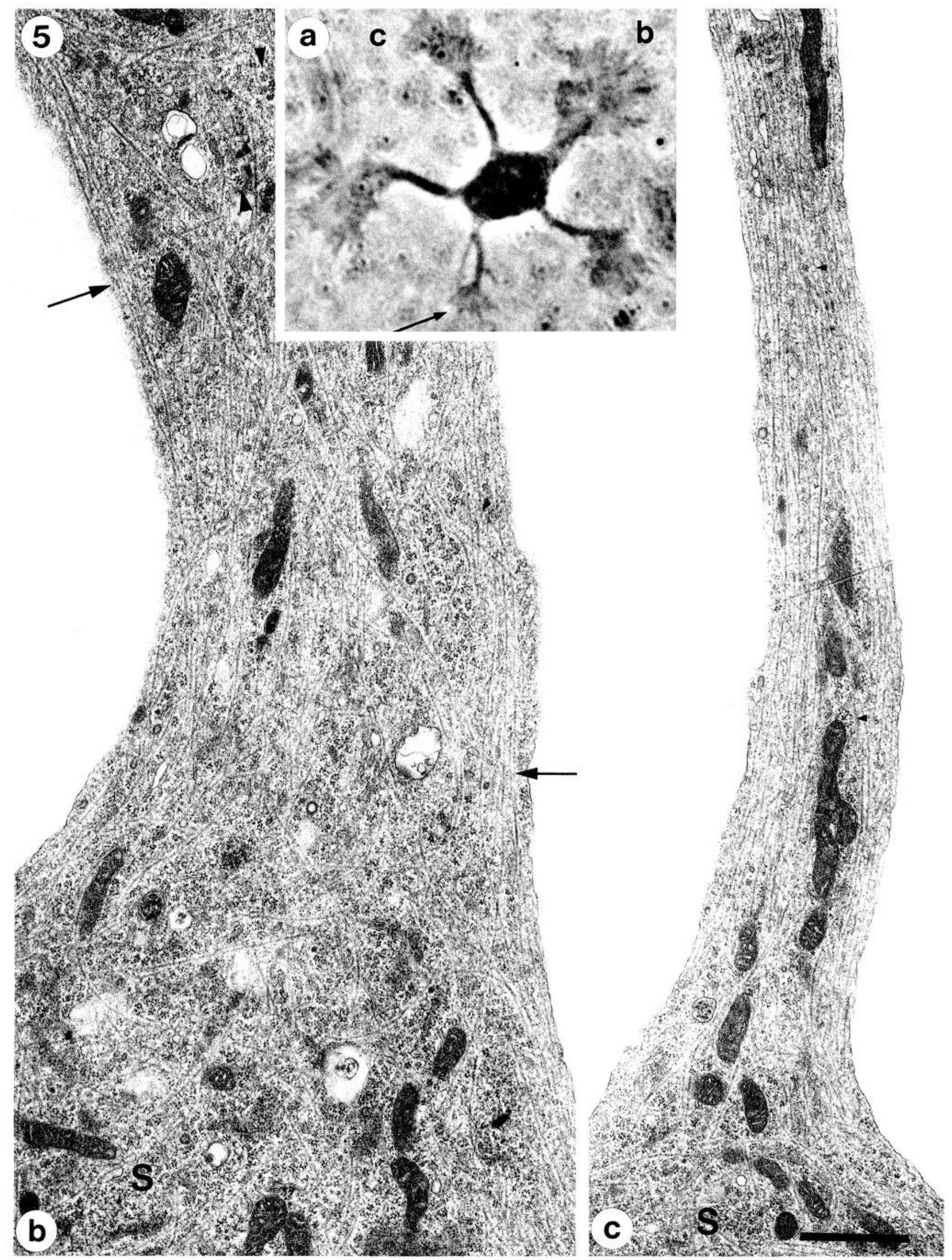



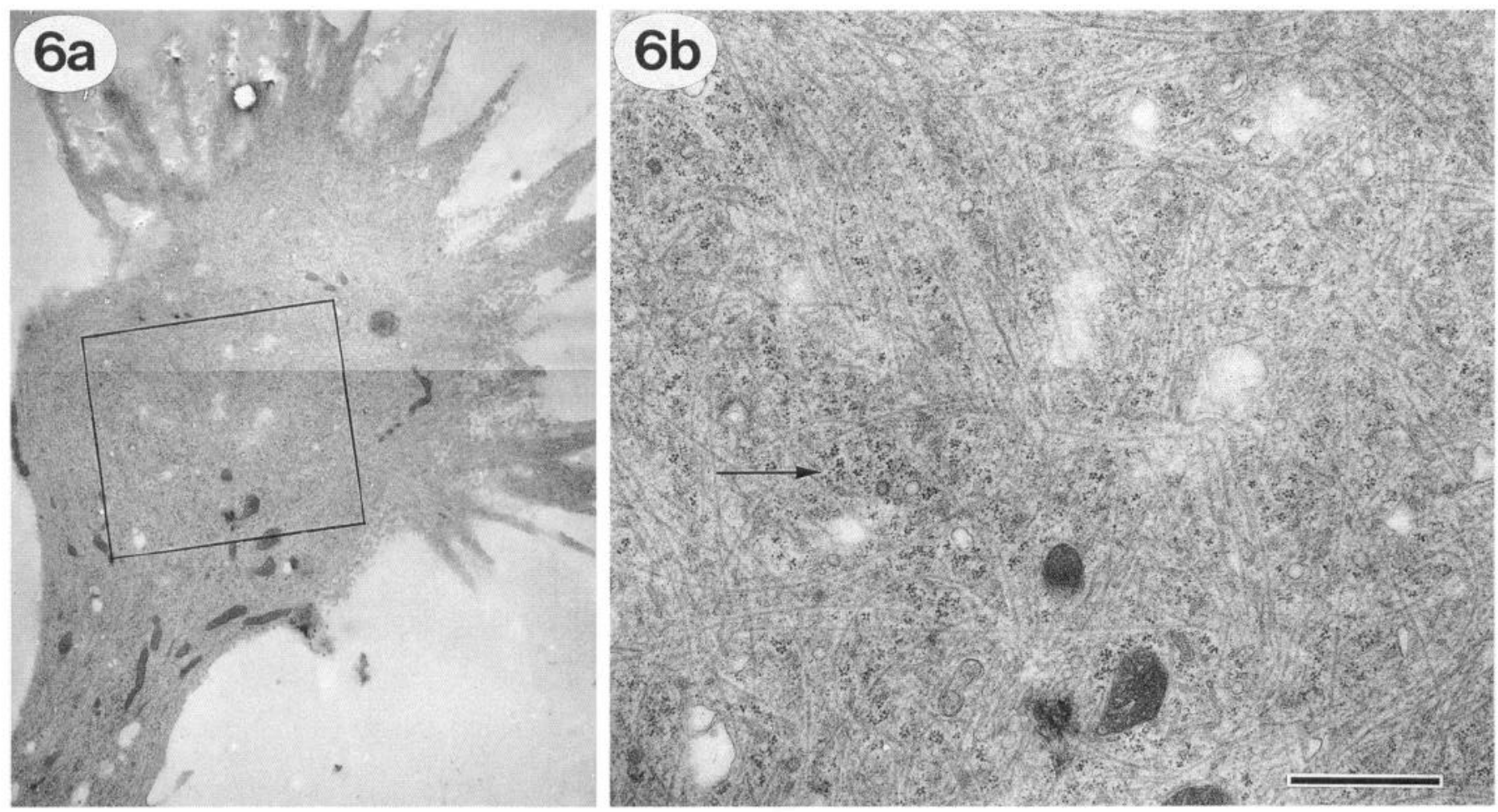

Figure 6. $a$, Growth cone of the wide minor process shown in Figure 5, $a$ and $b$. Magnification, 5000 $\times$. $b$, Higher magnification of boxed area in $a$. Growth cones on wide minor processes resemble the lamellipodia of stage 1 cells: they contain many polyribosomes (arrow) in a tangle of microtubules, and very few membranous organelles. In contrast, the distal portions and filopodia contain microfilaments and a granular background. Scale bar, $1 \mu \mathrm{m}$.

$30 \mu \mathrm{m}$ in length, that emerge at more-or-less uniform intervals around the circumference of the soma, giving the cell a symmetric appearance. The minor processes of stage 2 neurons varied somewhat in shape, from processes that were rather broad and flat, like extended lamellipodia, to processes that were narrower and appeared to be cylindrical, like definitive neurites (compare processes $\mathrm{b}$ and $\mathrm{c}$ in Fig. 5a). These variations were frequently seen among the different minor processes emerging from a single cell.

The ultrastructure of minor processes was also somewhat variable, and correlated with their light microscopic appearance. This is illustrated in Figure 5, which compares a wide and a narrow minor process, both arising from the same cell. Wide minor processes, which accounted for about $20 \%$ of the minor processes in the stage 2 cells we examined, resembled extensions of the cell body (Fig. $5 b$ ). The microtubule complex was disarrayed, and mitochondria and SER were randomly oriented and took a variety of shapes. The exception to this random organization was seen along the plasma membrane. There, a few microtubules were organized parallel to the axis of the neurite. Dense aggregates of polyribosomes also entered the base of wide minor processes. In the case of narrow minor processes (base thickness of $<\sim 2 \mu \mathrm{m}$ ) the transition from the soma was more abrupt (Fig. $5 c$ ). Microtubules became aligned parallel to the axis of the minor process at its base, and mitochondria and SER were typically elongated parallel to the microtubules. Ribosomes were present, but at a much lower density than in the cell body. Often they were seen in clusters together with other organelles. In general, there was considerable variability in the polyribosome density within minor processes, even within a single cell (compare Fig. $5 b, c$ ). We did not, however, observe consistent differences in polyribosome density between wide and narrow minor processes.

The growth cones of wide and narrow minor processes also differed somewhat in appearance (Figs. 6, 7). Growth cones on narrow minor processes were similar in ultrastructure to the growth cones of other types of cultured nerve cells (e.g., Yamada et al., 1971). The highly aligned microtubular array present in the neurite shaft ended at the base of the growth cone (Fig. 7). At this point microtubules splayed out in different directions, sometimes terminating at the base of filopodia, sometimes looping back toward the neurite shaft (Fig. $7 b$ ). It was also not unusual to find a microtubule extending deep into a growth cone filopodium, even to the tip. Mitochondria and small membranous elements were also occasionally observed, but by far the dominant component was a pervasive, floccular substance that was present throughout the growth cone and filled the filopodia. This material presumably represents the network of actin filaments, which are not well preserved by the aldehyde-osmium mixture used for fixation. In cells fixed for longer periods in glutaraldehyde before osmication (see Materials and Methods), distinct bundles of microfilaments could be seen in these regions. These frequently had a radial organization and extended into filopodia, an organization also seen when filamentous actin is visualized using fluorescent phalloidin (Goslin et al., 1989).

The growth cones of wide minor processes had a different appearance (Fig. 6). Whereas the periphery of these growth cones was similar to those found on narrow minor processes, the central region more closely resembled the somatic cytoplasm in its content and organization. It contained numerous polyribosomes and a swirling network of microtubules, together with mitochondria and profiles of SER. In this respect, the growth cones 

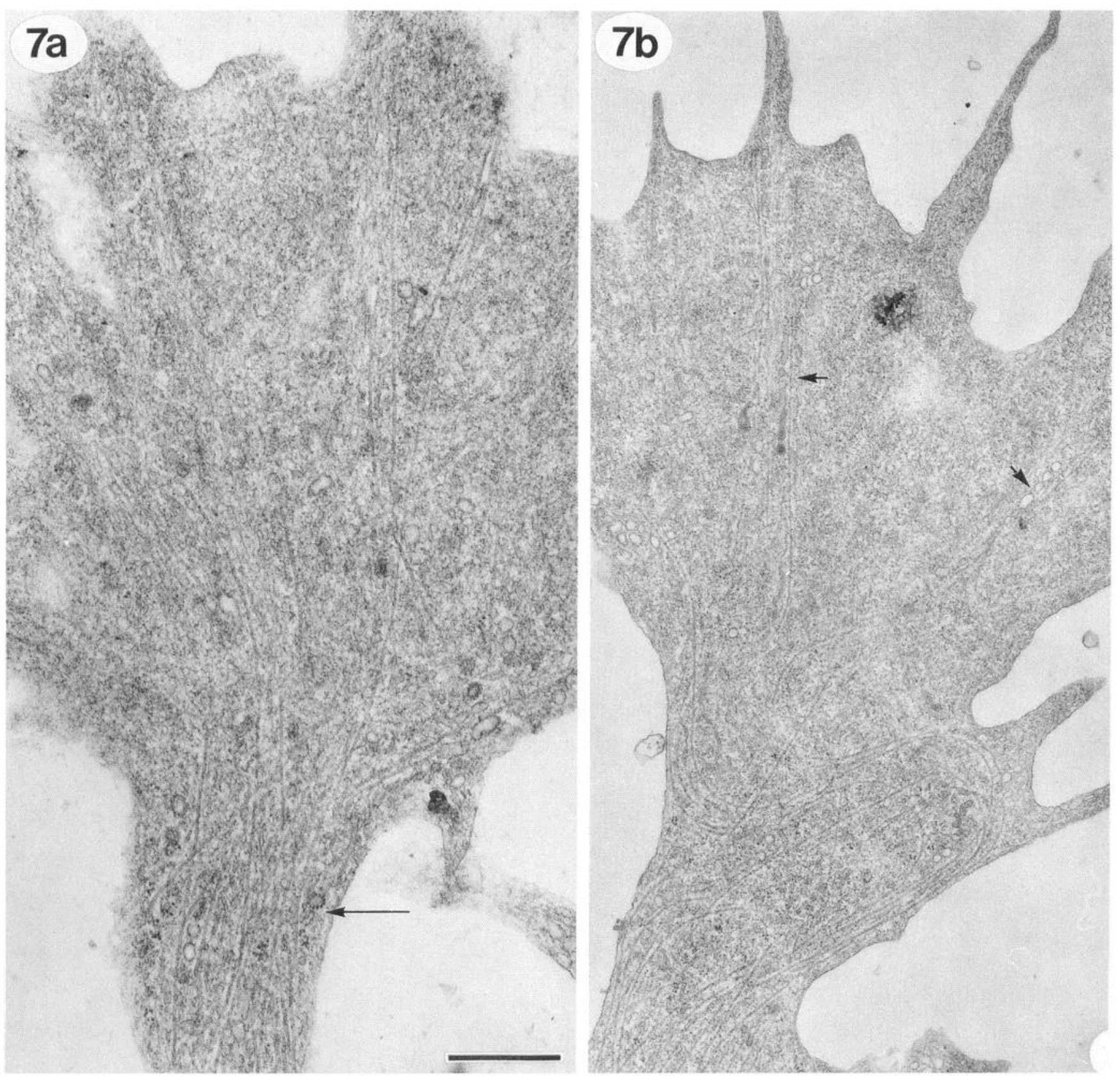

Figure 7. Growth cones of narrow minor processes. $a$, The growth cone shown in Figure $5 a$. Few microtubules enter the growth cone; those that do fan out toward the distal membrane. Polyribosomes are present in the shaft (arrow) but are scarce in the growth cone, as are membranous organelles. The growth cone is rounder than on a wide minor process with fewer microspikes and contains mostly a granular background. $b$, Another growth cone from a narrow minor process. As is typical, the growth cone contains mostly a flocculent background. In this case the microtubules in the shaft form a swirl at the base of the growth cone, reversing direction several times, but most do not enter the palm of the growth cone. Note the alignment of membranous organelles along microtubules in the palm of the growth cone (arrows). Scale bar, $1 \mu \mathrm{m}$.

of wide minor processes resembled the lamellipodia that surround the somata of stage 1 neurons (not shown).

\section{Developmental stage 3-the outgrowth of the axon}

Developmental stage 3 begins when one minor process begins to grow rapidly and continuously until it is significantly longer than the remaining minor processes. This long process is the axon, and already at this stage some cellular constituents exhibit a polarized distribution (Goslin and Banker, 1990). The axon can be identified when it is only $10-15 \mu \mathrm{m}$ longer than the other minor processes if the behavior of individual cells is monitored by time-lapse microscopy. However, we initially restricted our ultrastructural analysis to cells whose axons were four to five times longer than the remaining minor processes, in order to be certain of the identity of these processes without resorting to time-lapse observations.

At stage 3, the ultrastructural appearance of the axon was quite distinct from that of the remaining minor processes. The most obvious difference was that axons contained far fewer polyribosomes than did minor processes. Polyribosomes could still be found within the axon, but at a much lower density. Typically they occurred in small groups (one to four) either in 


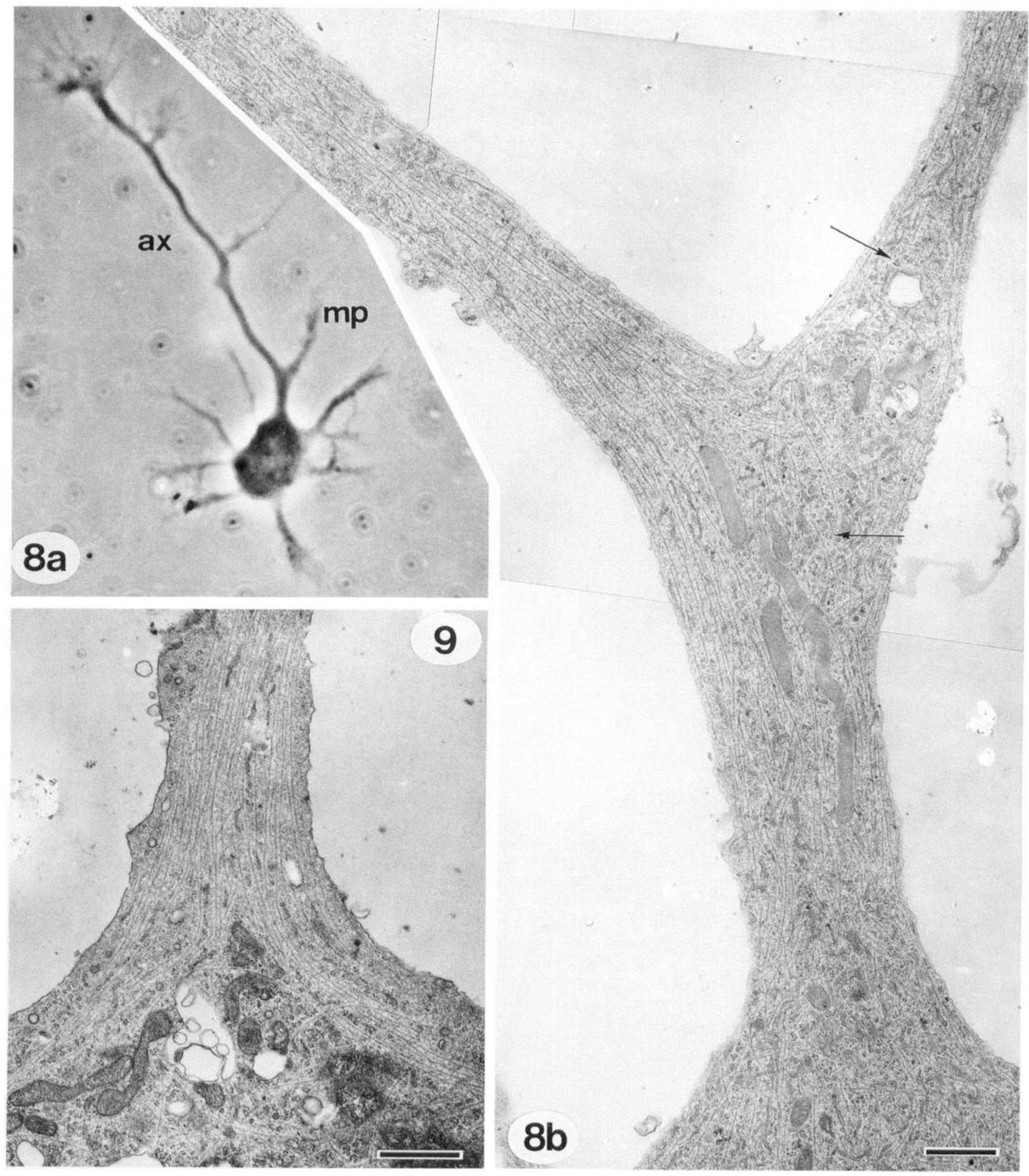

Figure 8. $a$, Light micrograph of a stage 3 neuron in which the axon $(a x)$ arises as a branch from a minor process $(m p)$. Magnification, $925 \times$. $b$, Electron micrograph of the branch point from where the axon arises. The stretch of shaft shared by the axon and the minor process, from the soma to the branch point, resembles a minor process. Distal to the branch point, the density of polyribosomes (arrows) in the axon drops precipitously, whereas the ultrastructure of the other branch remains unchanged. Scale bar, $1 \mu \mathrm{m}$.

Figure 9. Base of the axon of a stage 3 cell showing a sharp transition from soma to axon. Note the microtubules that funnel into axon from the periphery of the soma. Scale bar, $1 \mu \mathrm{m}$. 
the center of the axon, where they were often associated with mitochondria and SER (Fig. 10), or in small outpocketings along the plasma membrane.

The alignment of microtubules was also somewhat more regular in axons than in minor processes and the transition from somal to axonal cytoplasm was much more abrupt (Figs. 8b, 9). In the case of axons that originated directly from the cell body, there was a sharp delineation between the polyribosome-rich somatic cytoplasm and the axonal cytoplasm, which contained few polyribosomes. As microtubules entered the axon from the soma, they immediately assumed a parallel orientation, and membrane-bound organelles took on an elongated form, apparently orienting along the microtubules. In some cases the highly aligned bundles of microtubules just beneath the plasma membrane in the cell body themselves entered the axon; an extreme example of this is shown in Figure 9. In cases where the axon arose as a branch from a minor process, the shared segment between soma and branch point exhibited the polyribosome density and looser microtubule orientation characteristic of minor processes. However, at the point where the axonal branch arose, the transition was just as abrupt as when the axon arose directly from the soma (Fig. $8 b$ ), microtubules becoming more aligned and polyribosomes excluded. More distally within the axon, the microtubule array periodically exhibited a less organized appearance. This was particularly common at branch points. In such regions, mitochondria and elements of SER were also less elongated.

There were no pronounced ultrastructural differences between the minor processes of hippocampal neurons at stage 2 and those remaining at stage 3 . Narrow minor processes, with their more ordered cytoplasm, were more common at stage 3 than stage 2 , but some stage 3 neurons still possessed wide minor processes with "lamellipodial" growth cones. In comparison with the growth cones of minor processes, axonal growth cones appeared somewhat larger and more complex in shape, reflecting a greater number of lamellipodial and filopodial extensions. The "palm" of the growth cone, the region of transition between the highly ordered cytoplasm of the axon and the filopodial edge of the growth cone, also appeared larger in axonal growth cones. Within the palm, microtubules were much less organized than in the axon shaft, but bundles of microtubules were often present, sometimes extending to the leading edge. Occasional microtubules extended far into filopodia.

By far the most striking feature of axonal growth cones was a pronounced accumulation of membrane elements that resembled SER in the growth cone palm. These elements, which we shall refer to as reticular membrane, consisted of narrow, somewhat irregular tubules whose lumens were usually darkly stained (Figs. 11-13). In some cases the reticular membrane formed an irregular swirl within the palm of the growth cone (Fig. 11c), and sometimes extended into one or two of the filopodia (Fig. $12 a$ ). In other cases these membrane tubules took on a more parallel alignment, usually in association with one or two microtubules (Fig. 13c). Whereas individual membranous tubules with similar characteristics were also found in the minor processes and somata of neurons at this stage of development, a pronounced concentration of reticular membrane was observed only in axonal growth cones.

Given that axons of stage 3 cells had such a distinct ultrastructural appearance, we were interested in obtaining an estimate of how long it took for such changes to occur. Because elongation often pauses after the axon has become several times

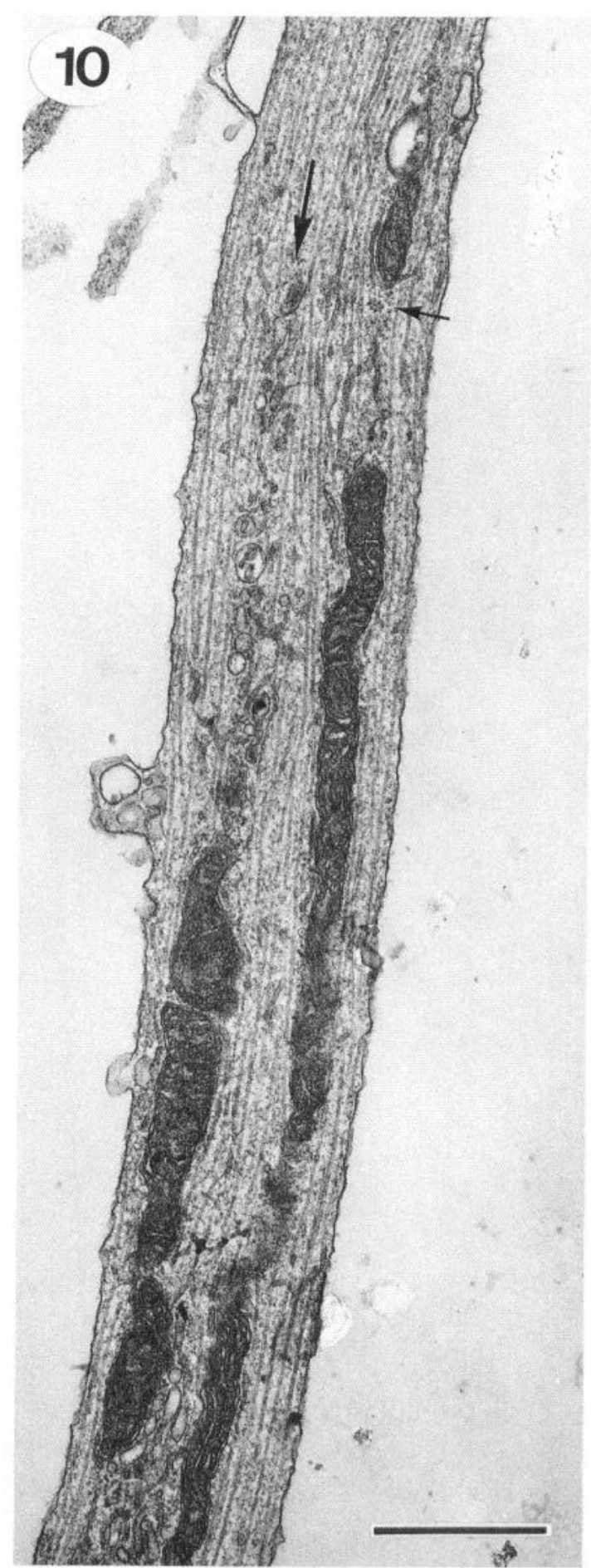

Figure 10. Portion of an axon from a neuron at stage 3 of development. Microtubules run parallel to the axolemma. Organelles such as mitochondria and SER are elongated and appear to be localized to channels between the microtubules (large arrow). Polyribosomes are rare and, when present, often are in small groups (small arrow) associated with other organelles, such as mitochondria. Scale bar, $1 \mu \mathrm{m}$.

longer than the remaining processes, and subsequent growth is intermittent, cells such as those just described might have formed axons anywhere from 2 to $12 \mathrm{hr}$ or more before they were fixed for EM. In order to examine the ultrastructure of cells shortly after they had formed an axon, we selected cells whose axons 


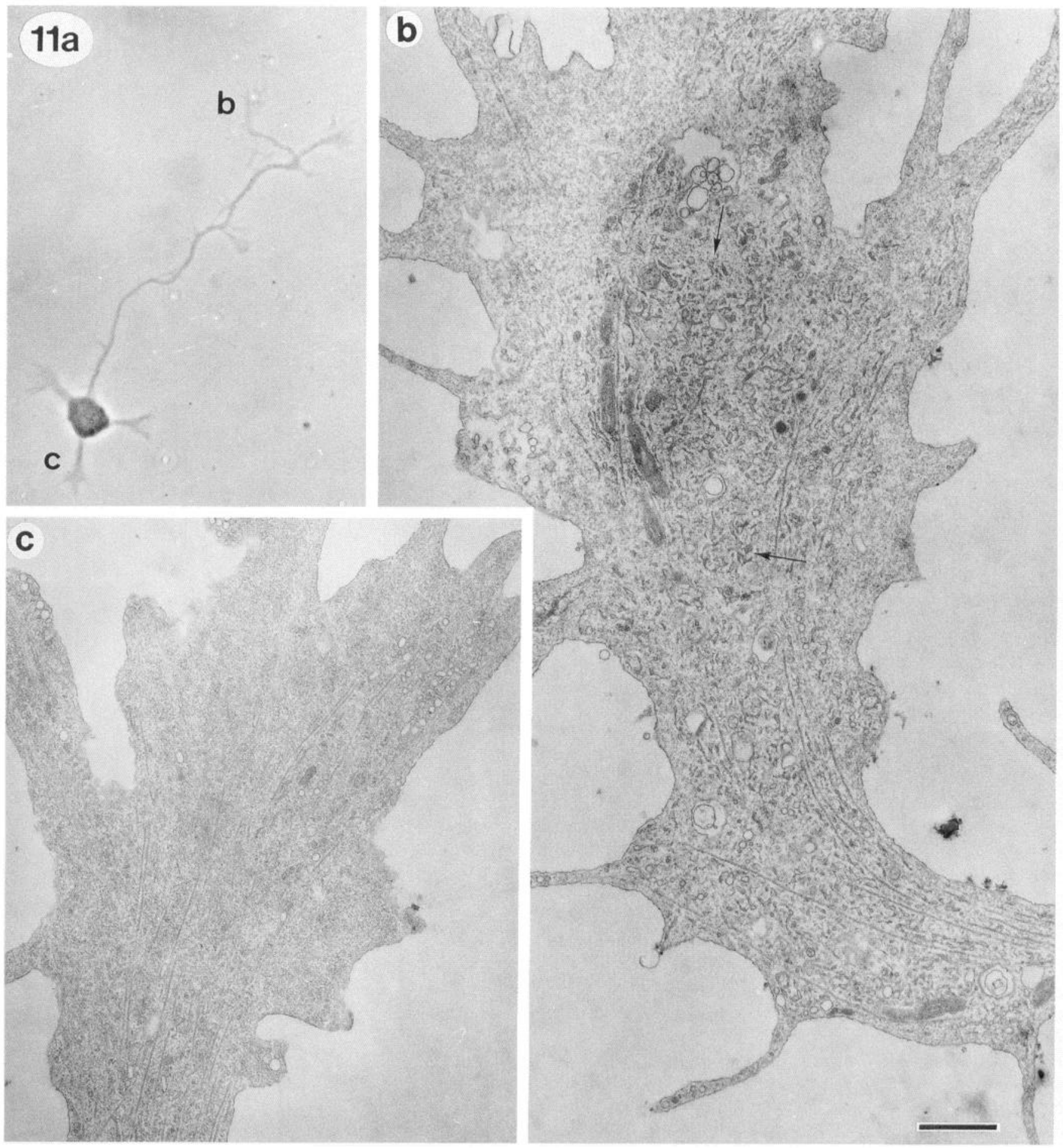

Figure 11. A comparison of the growth cones of axons and minor processes at stage 3 of development. $a$, Light micrograph of stage 3 neuron. The axonal growth cone (labeled $b$ ) is shown in panel $b$ and the minor process growth cone (labeled $c$ ) is shown in panel $c$. Magnification, $750 \times$. $b$, The axonal growth cone contains a bolus of membranous organelles. The most prominent of these are elongated elements, whose lumens are densely stained (arrows). In this thin section $(65 \mathrm{~nm})$ the curved, sometimes branched form of this membrane distinguishes it from round vesicles, primary and secondary endocytic compartments, and "blebs." $c$, The growth cones of minor processes of stage 3 neurons resemble those at stage 2 , with perhaps a few more organelles. The growth cone shown here is from a narrow minor process. Scale bar, $1 \mu \mathrm{m}$ for $b$ and $c$.

were only about twice the length of their minor processes. Based on previous time-lapse observations (Dotti et al., 1988; Goslin and Banker, 1990), we would estimate that such cells had formed axons only 1-3 hr previously. The axons of these cells had already acquired the distinctive features that set them apart from minor processes (Fig. 13). As with more developed stage 3 cells, their axons contained few polyribosomes and they exhibited an abrupt transition between soma and axon shaft, as evidenced by the rapid alignment of microtubules. In addition, the growth cones of these young axons were somewhat larger than those of minor processes and already contained a pronounced accumulation of reticular membrane. 

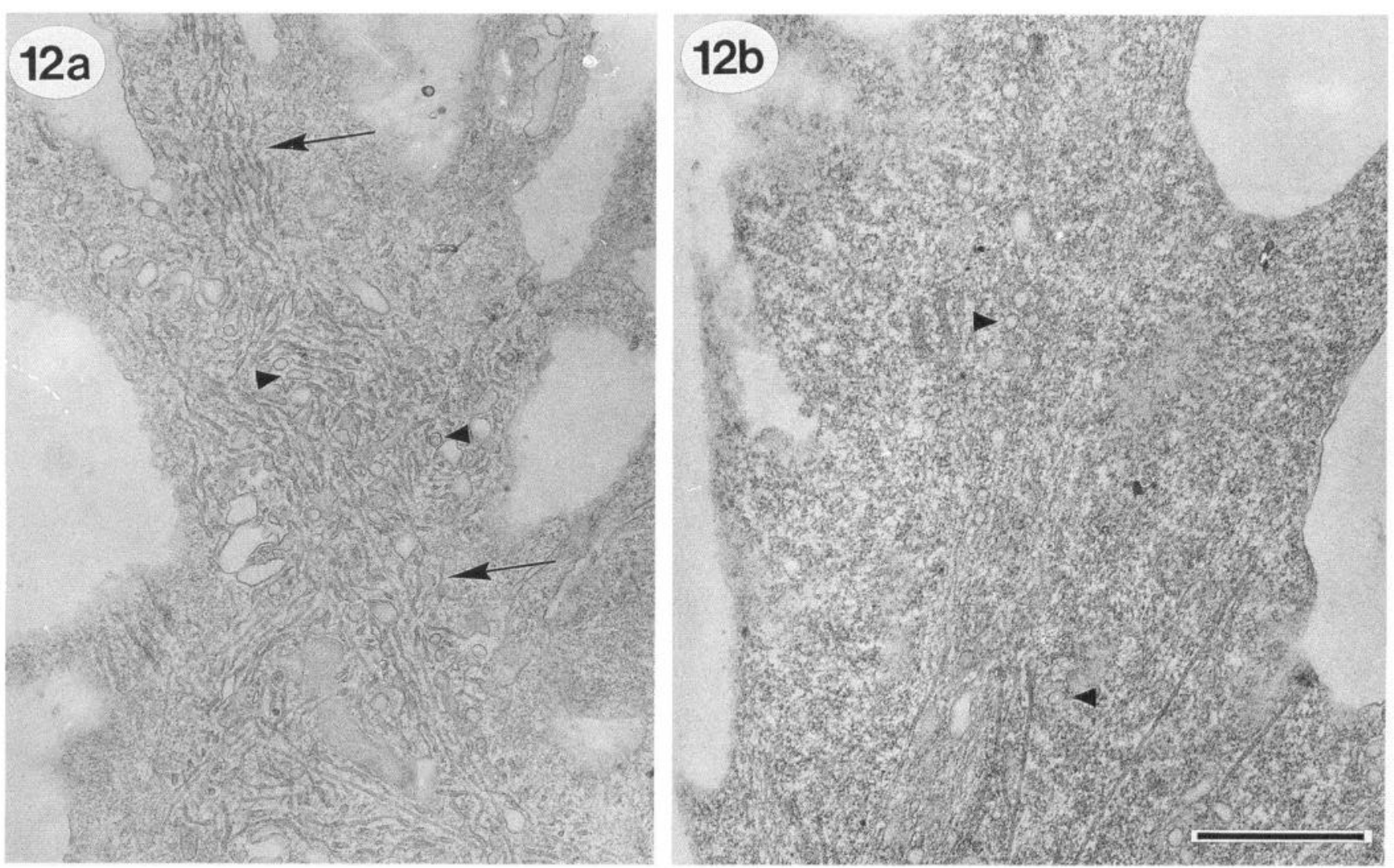

Figure 12. a, Axonal growth cone of a stage 3 neuron, illustrating the profusion of reticular membrane (arrows). Often a portion of this membrane extends into one of the filopodia or veils (arrow at top). Arrowheads indicate other types of membrane present. $b$, Membranous elements in the growth cone of a minor process (arrowheads). Most membranous organelles are round, with little, if any, that resemble the reticular membrane found in axonal growth cones. Scale bar, $1 \mu \mathrm{m}$ for $a$ and $b$.

\section{Quantitative analysis of organelle distribution during the establishment of polarity}

In order to document these conclusions more accurately, and to identify other possible differences in the ultrastructural characteristics of minor processes and axons that might not be obvious from simple inspection, we quantified the distribution of several cytoplasmic constituents in neurons at developmental stages 2 and 3. We measured the relative density of microtubules, polyribosomes, mitochondria, and all other membranebound organelles in the shafts of minor processes and axons (Tables 1-4). The last of these categories would include exocytotic and endocytotic vesicles, coated vesicles, and endoplasmic reticulum. As in the preceding section, stage 3 cells with short axons, which presumably originated within $1-3 \mathrm{hr}$ before fixation, were analyzed separately; these are referred to as "early" stage 3 cells.

As expected, there was an obvious difference between axons and minor processes with regard to their content of polyribosomes. The density of polyribosomes in axons was seven times less than in minor processes, and this difference was already apparent early in stage 3 . In addition, axons contained a somewhat higher density of mitochondria than minor processes, but because the density of mitochondria varied considerably within both types of processes, this difference was not statistically significant. Axons and minor processes exhibited no differences in the density of microtubules or of membranous organelles. There were no significant differences between minor processes of stage
2 and stage 3 cells in any of these measures, nor were there differences between axons of different lengths.

We also determined the relative amount of reticular membrane in the growth cones of axons and of minor processes (Table 5). Axonal growth cones contained about a fivefold higher density of these elements, a difference that was already apparent early in stage 3 .

\section{Discussion}

\section{The development of the minor processes}

The morphological development of hippocampal neurons in culture begins with the extension of minor processes, which eventually differentiate into axons and dendrites. Although minor processes differ somewhat in shape, previous studies have not indicated that these differences are correlated with differences in behavior or in immunostaining properties (e.g., Dotti et al., 1988; Goslin et al., 1990; Dotti and Banker, 1991). In the present study we have observed ultrastructural differences among minor processes that are correlated with their shape, and that may reflect maturational changes in minor processes, leading from a "lamellipodial" to an "neuritic" organization. In wide minor processes, microtubules are aligned along the plasma membrane, but within the center of the process they exhibit the more random organization typical of lamellipodia. In narrow minor processes, microtubules are aligned throughout. Since stage 1 neurons are initially surrounded by lamellipodia, and since we found that wide minor processes are common at stage 2 of development but are rare late in stage 3 , it seems reasonable 

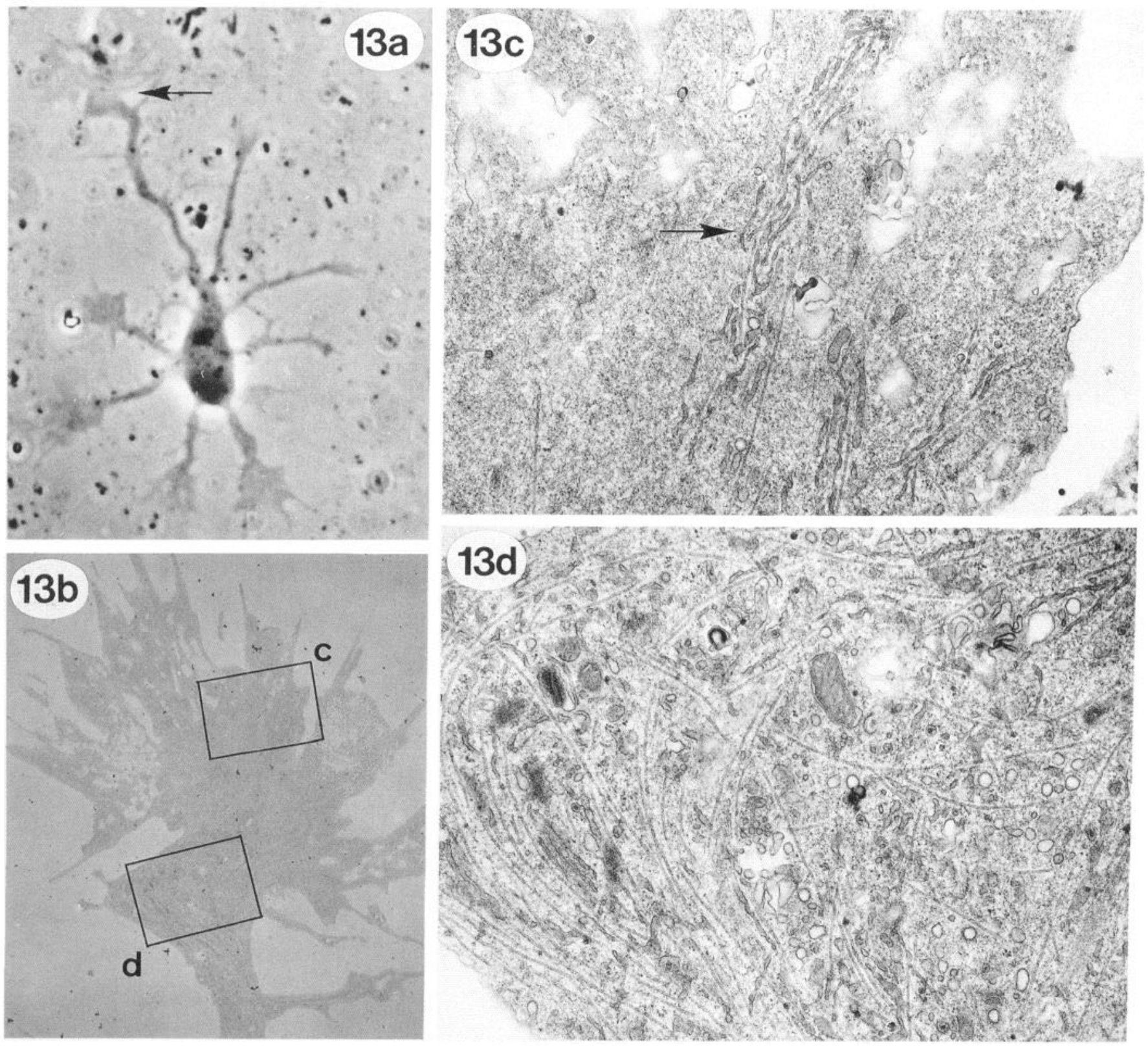

Figure 13. a, Light micrograph of a neuron early in stage 3 of development. The arrow indicates the growth cone of the presumptive axon. Magnification, $870 \times . b$, Low-power electron micrograph of the growth cone on the presumptive axon indicated in $a$. Boxes $c$ and $d$ are enlarged in panels $c$ and $d$, respectively. Magnification, 3300×. $c$ and $d$, Higher-magnification micrographs reveal reticular membrane $(c)$ and a swirl of microtubules at the base of the growth cone $(d)$. Same magnification as Figure 12.

to suggest that wide minor processes originate from lamellipodia and become narrower over time, ultimately taking on the organization of definitive neurites, with highly aligned microtubules. A related change appears to occur in the growth cones of minor processes. The growth cones of wide minor processes are literally a tangle of microtubules and other organelles, rather like lamellipodia themselves, whereas the growth cones of narrow minor processes contain only a few tracks of microtubules together with associated vesicles.

One cannot determine a causal relationship between the narrowing of the shaft and the increased organization of microtubules from static EM observations. However, these findings are consistent with the possibility that the stabilization or nucle- ation of the parallel array of microtubules in the minor process shaft begins along the plasma membrane, perhaps via membrane-associated cytoskeletal-binding proteins (Levine and Willard, 1981; Lazarides and Nelson, 1983; Ranscht et al., 1984; Stephens, 1986). The subsequent activation of cross-linking proteins (Hirokawa, 1982; Sasaki et al., 1983; Stevens et al., 1988) may then be responsible for constricting the minor process shaft by "recruiting" microtubules into the parallel array characteristic of narrow minor processes and mature dendrites. The changes in the organization of minor process growth cones might occur if elongation of the neurite plasma membrane stayed apace with the rate of delivery of microtubules and other components to the tips (Tanaka and Kirschner, 1991). 
Table 1. Density of polyribosomes in the shafts of axons and minor processes $\left(\# / \mu \mathrm{m}^{2}\right)$

\begin{tabular}{lll} 
& Minor processes & Axons \\
\hline Stage 2 & $2.28 \pm 0.72$ & - \\
Stage 3 (early) & $1.79 \pm 0.39$ & $0.28 \pm 0.17^{*}$ \\
Stage 3 & $1.89 \pm 0.90$ & $0.25 \pm 0.20^{*}$
\end{tabular}

Values shown are means \pm SD. Eight cells were analyzed at each age.

* Significantly different from minor processes $(p \leq 0.001)$.

\section{Differentiation of the axon}

By light microscopic methods there are no cues to distinguish which of the minor processes of a stage 2 neuron will differentiate into the axon. Although in the present investigation we found that the ultrastructure of the minor processes was quite variable, one minor process per neuron was not consistently more axonlike than the others, or in any way singularly different. However, two characteristics of axonal differentiation - a decrease in polyribosome density and an increased density of membranous organelles in the growth cone-were already present at the earliest time the axon was identifiable (early stage 3 ). Thus, ultrastructural differentiation must have occurred quite rapidly at the onset of axonal specification.

The paucity of polyribosomes is one of the most reliable charactcristics for distinguishing axons from dendrites both in situ (Peters et al., 1991) and in culture (Bartlett and Banker, 1984a; Davis et al., 1987). In this study we have found that minor processes, like dendrites, contain polyribosomes throughout their length whereas polyribosome density is reduced in the growing axon. A few polyribosomes persisted distally in the longer axons of stage 3 neurons; these ribosomes most likely were present in the minor process prior to its differentiation into an axon and were carried passively to more distal locations by the rapid elongation. The large drop in ribosome density in the emergent axons suggests that the mechanisms responsible for the exclusion of ribosomes are present at the initial stages of axonal outgrowth. These observations are consistent with previous studies of developing axons in situ (Tennyson, 1970; Peters and Feldman, 1973; Hinds and Hinds, 1974).

With regard to the development of neuronal polarity, these obscrvations demonstrate that exclusion of ribosomes is an early event. On the other hand, developing axons and axonal growth cones, both in situ and in culture, do contain occasional ribosomes, whereas ribosomes are extremely rare in mature axons. Thus, from the standpoint of neural development, the ribosomes that are present in immature axons may be capable of limited protein synthesis, which could play an important role in axonal growth (e.g., see Ginzburg, 1991).

One other obvious difference between axons and dendrites concerns their microtubule cytoskeleton. In mature axons mi-

\begin{tabular}{|c|c|c|}
\hline & Minor processes & Axons \\
\hline Stage 2 & $3.72 \pm 0.47$ & - \\
\hline Stage 3 (early) & $4.07 \pm 0.67$ & $4.35 \pm 0.88$ \\
\hline Stage 3 & $3.46 \pm 0.53$ & $4.35 \pm 0.69$ \\
\hline
\end{tabular}

Values shown are means \pm SD. Eight cells were analyzed at each age.
Table 3. Relative areal density of intracellular membranes in the shafts of axons and minor processes (arbitrary units)

\begin{tabular}{lll} 
& Minor processes & Axons \\
\hline Stage 2 & $3.04 \pm 0.62$ & - \\
Stage 3 (early) & $3.95 \pm 0.48$ & $4.03 \pm 0.96$ \\
Stage 3 & $3.76 \pm 1.11$ & $3.06 \pm 0.47$
\end{tabular}

Values shown are means \pm SD. Eight cells were analyzed at each age.

crotubules form tightly spaced bundles, whereas dendritic microtubules are more widely spaced (Bartlett and Banker, 1984a,b; Black, 1987), and axons and dendrites contain a distinct complement of microtubule-associated proteins (Tucker, 1990). Based on observations of mesencephalic and cerebellar cultures, it has been hypothesized that differences in the density or stability of microtubules in young axons and dendrites play an important role in the development of neuronal polarity (Caceres and Kosik, 1990; Rousselct ct al., 1990). This does not appear to be the case for hippocampal neurons. We observed no difference in microtubule density between the axon and the remaining minor processes, nor were there differences in average microtubule density between cells that had already formed axons and those that had not. The differences in microtubule density and in microtubule-associated protein composition between mature axons and dendrites apparently arise later in development, well after polarity is established (see Bartlett and Banker, 1984a,b; Caceres et al., 1986). Nor do axons and minor processes differ in microtubule stability, at least as assessed using antibodies against posttranslationally modified tubulin (Dotti and Banker, 1991). Of course these negative results do not rule out the possibility that other differences in the functional properties of axonal microtubules, such as their association with motor proteins, could be critical for the rapid growth rate of axons or for the exclusion of ribosomes.

Microtubule density in the growth cone was not quantified since the volume of the growth cone, on which microtubule density is based, would be expected to vary as veils of membrane extend and contract (Burmeister et al., 1988). Tanaka and Kirschner (1992) also noted little correlation between growth cone volume or shape and microtubule number. Qualitatively, the growth cone of the emerging axon is best described as a swirling mass of microtubules and reticular membrane. This is quite different from the modest excursion of microtubules into the growth cones of narrow minor processes. In the terminology of Tanaka and Kirschner (1992), the axonal growth cones contain "looped" and "bundled" microtubules whereas those in the growth cones on minor processes are more "splayed." This may reflect differences in the growth patterns of the two types of

Table 4. Relative density of mitochondria in the shafts of axons and minor processes (arbitrary units)

\begin{tabular}{lll} 
& Minor processes & Axons \\
\hline Stage 2 & $1.45 \pm 0.93$ & - \\
Stage 3 (early) & $1.53 \pm 0.63$ & $3.77 \pm 3.09^{*}$ \\
Stage 3 & $1.08 \pm 1.06$ & $2.87 \pm 1.94^{* *}$ \\
\hline
\end{tabular}

Values shown are means \pm SD. Eight cells were analyzed at each age.

${ }^{*} p<0.04$.

$* * p<0.10$. 
Table 5. Relative density of reticular membrane in the growth cones of axons and minor processes (arbitrary units)

\begin{tabular}{lll} 
& Minor processes & Axons \\
\hline Stage 2 & $0.52 \pm 0.39$ & - \\
Stage 3 (early) & $0.85 \pm 0.37$ & $3.44 \pm 1.19^{*}$ \\
Stage 3 & $0.58 \pm 0.19$ & $3.68 \pm 1.49^{*}$ \\
\hline
\end{tabular}

Values shown are means \pm SD. Eight cells were analyzed at each age.

* Significantly different from minor processes $(p<0.001)$.

processes - the steady state dynamics of minor process growth versus the rapid net growth in the axon. Thus, although the density of microtubules in the shaft may not change as the axon emerges, there may be a change in the associated kinetics or stability of microtubules at the tip that allow the microtubules in the axon to extend into the growth cone, perhaps growing faster than the membrane can expand to accommodate them.

\section{Endoplasmic reticulum in the axonal growth cone}

The most surprising finding from this work was the pronounced concentration of endoplasmic reticulum-like membranes within the axonal growth cone compared with the growth cones of minor processes. The presence of SER in axonal growth cones is not in itself unusual. Similar elements have been described in many previous ultrastructural studies of growth cones and varicosities as seen in both conventionally prepared, thin-sectioned material (Bunge, 1977; Luckenbill-Edds et al., 1979; Kataoka et al., 1980; Mercurio and Holtzman, 1982; Aletta and Greene, 1988) and in whole-mounts (Dailey and Bridgman, 1989). The stacks of "lumenless" membranc identificd by Cheng and Reese $(1985,1987)$ in rapidly frozen axonal growth cones may correspond to the same elements. The novelty of our observations is that during the development of polarity, these elements are uniquely associated with the growth cone of a single process, the emerging axon. On this basis it is tempting to suggest that these elements either are necessary to support the rapid growth characteristic of axons, or are a consequence of rapid growth. In this regard it will be of interest to determine if a distinct concentration of endoplasmic reticulum appears in the growth cones of minor processes during stage 4 of development, when they begin to elongate and acquire dendritic characteristics.

Although the presence of endoplasmic reticulum in growth cones has been known for over 20 years, its functional significance remains uncertain. Because the addition of new membrane required to support clongation is belicved to occur in growth cones, it has been suggested that these elements of endoplasmic reticulum may represent a pool of precursor membrane available for addition to the plasma membrane (Yamada et al., 1971; Cheng and Reese, 1987). Alternatively, these elements may simply perform one or more of the functions that are characteristic of the SER generally, but that might be of particular importance for axonal elongation. For example, the concentration of cytosolic calcium in growth cones, which can be regulated by sequestration within the endoplasmic reticulum, is believed to play an important role in the control of axonal elongation (Connor, 1986; Silver et al., 1989; Kater and Mills, 1991). Dailey and Bridgman (1989) have raised the possibility that local concentrations of endoplasmic reticulum within the growth cone could permit local differences in calcium concentration that might influence the properties of nearby cytoskeletal elements. In addition, the SER is the dominant site of lipid synthesis within cells. Vance et al. (1991) have recently shown that axons, separated from their cell bodies, are capable of synthesizing phosphatidylcholine, phosphatidylethanolamine, and sphingomyelin, and have raised the possibility that a significant fraction of the membrane required for elongation may be locally synthesized. Our observation that in polarized cells these elements are preferentially concentrated in the growth cone of the only process that is rapidly extending is consistent with any of these possibilities.

Our observations emphasize the need to determine the functional significance of endoplasmic reticulum in the growth cone and to elucidate the mechanisms that selectively transport this membrane to the axonal growth cone and at the same time prohibit polyribosomes from entering the newly formed axon.

\section{References}

Aletta JM, Greene LA (1988) Growth cone configuration and advance: a time-lapse study using video-enhanced differential interference contrast microscopy. J Neurosci 8:1425-1435.

Baas PW, Deitch JS, Black MM, Banker GA (1988) Polarity orientation of microtubules in hippocampal neurons: uniformity in the axon and nonuniformity in the dendrite. Proc Natl Acad Sci USA 85:8335-8339.

Baas PW, Black MM, Banker GA (1989) Changes in microtubule polarity orientation during the development of hippocampal neurons in culture. J Cell Biol 109:3085-3094.

Banker G, Goslin K (1991) Culturing nerve cells. Cambridge, MA: MIT Press.

Bartlett WP, Banker GA (1984a) An electron microscopic study of the development of axons and dendrites by hippocampal neurons in culture. I. Cells which develop without intercellular contacts. J Neurosci 4:1944-1953.

Bartlett WP, Banker GA (1984b) An clectron microscopic study of the development of axons and dendrites by hippocampal neurons in culture. II. Synaptic relationships. J Neurosci 4:1954-1965.

Binder LI, Frankfurter A, Rebhun LI (1985) The distribution of tau in the mammalian central nervous system. J Cell Biol 101:13711378.

Black MM (1987) Comparison of the effects of MAP2 and tau on the packing density of in vitro assembled microtubules. Proc Natl Acad Sci USA 84:7783-7787.

Bottenstein JE, Sato GH (1979) Growth of a rat neuroblastoma cell line in serum-free supplemented medium. Proc Natl Acad Sci USA $76: 514-519$

Boyles J, Fox JEB, Phillips DR, Stenberg PE (1985) Organization of the cytoskeleton in resting, discoid platelets: preservation of actin filaments by a modified fixation that prevents osmium damage. J Cell Biol 101:1463-1472.

Bunge MB (1977) Initial endocytosis of peroxidase or ferritin by growth cones of cultured nerve cells. J Neurocytol 6:407-439.

Burmeister DW, Chen M, Bailey CH, Goldberg DJ (1988) The distribution and movement of organelles in maturing growth cones: correlated video-enhanced and electron microscopic studies. J Neurocytol 17:783-795.

Caceres A, Kosik K (1990) Inhibition of neurite polarity by tau antisense oligonucleotides in primary cerebellar neurons. Nature 343: $461-463$.

Caceres A, Binder LI, Payne MR, Bender P, Rebhun L, Steward O (1984) Differential subcellular localization of tubulin and the microtubule associated protein MAP2 in brain tissue as revealed by immunocytochemistry with monoclonal hybridoma antibodies. J Neurosci 4:394-410.

Caceres A, Banker GA, Binder L (1986) Immunocytochemical localization of tubulin and microtubule-associated protein 2 during the development of hippocampal neurons in culture. J Neurosci 6:714 722.

Cheng TPO, Reese TS (1985) Polarized compartmentalization of organelles in growth cones from developing optic tectum. J Cell Biol 101:1473-1480.

Cheng TPO, Reese TS (1987) Recycling of plasmalemma in chick tectal growth cones. J Neurosci 7:1752-1759. 
Cheramy A, Leviel V, Glowinski J (1981) Dendritic release of dopamine in the substantia nigra. Nature 289:537-542.

Connor JA (1986) Digital imaging of free calcium changes and of spatial gradients in growing processes in single, mammalian central nervous system cells. Proc Natl Acad Sci USA 83:6179-6183.

Corey DP, Stevens CF (1983) Science and technology of patch-rccording electrodes. In: Single-channel recording (Sakmann B, Neher E, eds), pp 53-68. New York: Plenum.

Dailey ME, Bridgman PC (1989) Dynamics of the endoplasmic reticulum and other membranous organelles in growth cones of cultured neurons. J Neurosci 9:1897-1909.

Davis L, Banker GA, Steward O (1987) Selective dendritic transport of RNA by hippocampal neurons in culture. Nature 330:477-479.

De Camilli P, Miller P, Navone F, Theurkauf WE, Vallee RB (1984) Distribution of microtubule associated protein 2 (MAP2) in the nervous system of the rat studied by immunofluorescence. Neuroscience 11:819-846.

Dotti CG, Banker GA (1987) Experimentally induced alteration in the polarity of developing neurons. Nature 330:254-256.

Dotti CG, Banker GA (1991) Intracellular organization of hippocampal neurons during the development of neuronal polarity. J Cell Sci 100[Suppl 15]:75-84.

Dotti CG, Banker GA, Binder LI (1987) The expression and distribution of the microtubule-associated proteins tau and microtubuleassociated protein 2 in hippocampal neurons in the rat in situ and in cell culture. Neuroscience 23:121-130.

Dotti CG, Sullivan CA, Banker GA (1988) The establishment of polarity hy hippocampal neurons in culture. J Neurosci 8:1454-1468.

Fletcher TL, Cameron P, De Camilli P, Banker GA (1991) The distribution of synapsin I and synaptophysin in hippocampal neurons developing in culture. $J$ Neurosci 11:1617-1626.

Garner CC, Tucker RP, Matus A (1988) Selective localization of messenger RNA for cytoskeletal protein MAP2 in dendrites. Nature 336: 674-677.

Ginzburg I (1991) Neuronal polarity: targeting of microtubule components into axons and dendrites. Trends Biochem 16:257-261.

Goslin K, Banker G (1989) Experimental observations on the development of polarity by hippocampal neurons in culture. J Cell Biol 108:1507-1516.

Goslin K, Banker GA (1990) Development of neuronal polarity: changes in the distribution of GAP-43 correlate with changes in the expression of polarity during normal development and under experimental conditions. J Cell Biol 110:1319-1332.

Goslin K, Banker GA (1991) Rat hippocampal neurons in low-density culture. In: Culturing nerve cells (Banker G, Goslin K, eds), pp 251281. Cambridge, MA: MIT Press.

Goslin K, Birgbauer E, Banker G, Solomon F (1989) The role of cytoskeleton in organizing growth cones: a microfilament-associated growth cone component depends upon microtubules for its localization. J Cell Biol 109:1621-1631.

Goslin K, Schreyer DJ, Skene JHP, Banker G (1990) Changes in the distribution of GAP-43 during the development of neuronal polarity. J Neurosci 10:588-602.

Hasty DL, Hay ED (1978) Freeze-fracture studies of the developing cell surface. II. Particle-free membrane blisters on glutaraldehydefixed corneal fibroblasts are artifacts. J Cell Biol 78:756-768.

Hinds JW, Hinds PL (1974) Early ganglion cell differentiation in the mouse retina: an electron microscopic analysis utilizing serial sections. Dev Biol 37:381-416.

Hirokawa N (1982) Cross-linker system between neurofilaments, microtubules and membranous organelles in frog axons revealed by the quick-freeze deep-etching method. J Cell Biol 94:129-142.

Huber G, Matus A (1984) Differences in the cellular distributions of two microtubule-associated proteins, MAP1 and MAP2, in rat brain. J Neurosci 4:151-160.

Kataoka S, Sandquist D, Williams L, Williams TH (1980) Growth cones in differentiated neuroblastoma: a time-lapse cinematographic and electron microscopic study. J Neurocytol 9:591-602.
Kater SB, Mills LR (1991) Regulation of growth cone behavior by calcium. J Neurosci 11:891-899.

Lazarides E, Nelson WJ (1983) Erythrocyte and brain forms of spectrin in cerebellum: distinct membrane-cytoskeletal domains in neurons. Science 220:1295-1296.

Levine J, Willard M (1981) Fodrin: axonally-transported polypeptides associated with the internal periphery of many cells. J Cell Biol 90: 631-643.

Llinas R, Sugimori M (1980) Electrophysiological properties of in vitro Purkinje cell dendrites in mammalian cerebellar slices. J Physiol (Lond) 305:197-213.

Luckenbill-Edds L, Van Horn C, Greene LA (1979) Fine structure of initial outgrowth of processes induced in a pheochromocytoma cell line (PC12) by nerve growth factor (NGF). J Neurocytol 8:493-511.

Masurovsky EB, Bunge RP (1968) Fluoroplastic coverslips for longterm nerve tissue culture. Stain Tech 43:161-165.

Mercurio AM, Holtzman E (1982) Smooth endoplasmic reticulum and other agranular reticulum in frog retinal photoreceptors. J Neurocytol 11:263-293.

Nowakowski RS, Rakic P (1979) The mode of migration of ncurons to the hippocampus: a Golgi and electron microscopic analysis in foetal rhesus monkey. J Neurocytol 8:697-718.

Peters A, Feldman M (1973) The cortical plate and molecular layer of the late rat fetus. $Z$ Anat Entwicklungsgesch 141:3-37.

Peters A, Palay SL, Webster HdeF (1991) The fine structure of the nervous system: the neurons and supporting cells, $3 \mathrm{~d}$ ed. New York: Oxford UP.

Ranscht B, Moss DJ, Thomas C (1984) A neuronal surface glycoprotein associated with the cytoskeleton. J Cell Biol 99:1803-1813.

Rees RP, Reese TS (1981) New structural features of freeze-substituted neuritic growth cones. Neuroscience 6:247-254.

Rousselet A, Autillo-Touati A, Araud D, Prochiantz A (1990) In vitro regulation of neuronal morphogenesis and polarity by astrocyte-derived factors. Dev Biol 137:33-45.

Sargent PB (1989) What distinguishes axons from dendrites? Neurons know more than we do. Trends Neurosci 12:203-205.

Sasaki S, Stevens JK, Bodick N (1983) Serial reconstruction of microtubular arrays within dendrites of the cat retinal ganglion cell: the cytoskeleton of a vertebrate dendrite. Brain Res 259:193-206.

Shelton E, Mowzcko WE (1978) Membrane blisters. A fixation artifact. A study in fixation for scanning electron microscopy. Scanning $1: 166-$ 173.

Shepherd GM (1979) Functional analysis of local circuits in the olfactory bulb. In: The neurosciences, fourth study program (Schmitt FO, Worden FG, eds), pp 129-143. Cambridge, MA: MIT Press.

Silver RA, Lamb AB, Bolsover SR (1989) Elevated cytosolic calcium in the growth cone inhibits neurite elongation in neuroblastoma cells: correlation of behavioural states with cytosolic calcium concentration. J Neurosci 9:4007-4020.

Stephens RE (1986) Membrane tubulin. Biol Cell 57:95-109.

Stevens JK, Irogadis J, Jacobs JR (1988) Development and control of axial neurite form: a serial electron microscopic analysis. In: Intrinsic determinants of neuronal form and function (Lasek RJ, Black MM, eds), pp 115-145. New York: Liss.

Tanaka EM, Kirschner MW (1991) Microtubule behavior in the growth cones of living neurons during axon elongation. J Cell Biol 115:345363.

Tennyson VM (1970) The fine structure of the axon and growth cone of the dorsal root neuroblast of the rabbit embryo. J Cell Biol 44:6287.

Tucker RP (1990) The roles of microtubule-associated proteins in brain morphogenesis: a review. Brain Res Rev 15:101-120.

Vance JE, Pan D, Vance DE, Campenot RB (1991) Biosynthesis of membrane lipids in rat axons. J Cell Biol 115:1061-1068.

Weibel ER (1979) Stereological methods. London: Academic.

Yamada KM, Spooner BS, Wessells NK (1971) Ultrastructure and function of growth cones and axons of cultured nerve cells. J Cell Biol 49:614-635. 